\title{
Knowledge, attitudes, and psychosocial impacts among Brazilian Pediatric Dentists during COVID-19 pandemic
}

\author{
Carolina Paes TORRES(a) (iD) \\ Elisangela Aparecida da Silva LIZZ|(b) \\ Maria Cristina BORSATTO(a) (D) \\ Paulo NELSON-FILHO(a) (iD \\ Andiara DE ROSSI(a) (D) \\ Kranya Victoria DÍAZ-SERRANO(a) \\ Aldevina Campos Freitas de \\ BARROS(a) $^{(i D}$ \\ Francisco Wanderley Garcia \\ PAULA-SILVA(a) iD \\ Fabrício Kitazono de CARVALHO(a) (iD \\ Raquel Assed Bezerra SILVA(a) \\ Lea Assed Bezerra SILVA(a) (iD \\ Marília Pacífico LUCISANO(a) (D) \\ Alexandra Mussolino QUEIROZ(a)
}

(a) Universidade de São Paulo - USP, School of Dentistry of Ribeirão Preto, Department of Pediatric Dentistry, University of São Paulo, Ribeirão Preto, SP, Brazil.

(b) Universidade Tecnológica Federal do Paraná - UTFPR, Department of Mathematics, Cornélio Procópio, PR, Brazil.

Declaration of Interests: The authors certify that they have no commercial or associative interest that represents a conflict of interest in connection with the manuscript.

\section{Corresponding Author:}

Carolina Paes Torres

E-mail: caroltorres@forp.sp.br

htpps://doi.org/10.1590/1807-3107bor-2022.vol36.0028

Submitted: May 4, 202

Accepted for publication: October 28, 2021

Last revision: November 23, 2021
Abstract: In this study, we evaluated the knowledge, attitudes, and psychosocial impacts among Brazilian pediatric dentists during the COVID-19 pandemic. A cross-sectional study with primary data collection was carried out using an online structured questionnaire. Data were submitted to descriptive analysis by using absolute and relative frequencies. A chi-square test was used for association analysis and log-linear regression models to estimate the prevalence ratio (5\%). The population comprised mostly women and knowledge regarding COVID-19 was satisfactory (above 80\% in most items). N95 masks and faceshields were used, albeit $64.22 \%$ reported difficulty in providing dental care to children due to the need for extra Personal Protective Equipment. Thirty eight percent provided urgency/emergency dental care, $59.78 \%$ performed invasive procedures, $59.56 \%$ used high speed handpieces, $8.44 \%$ started using cariostatics, and $6.22 \%$ introduced the use of chemomechanical caries removal agents. Fear for the future $(P R=1.21)$ and use of medications (for anxiety, depression, or insomnia) increased $(\mathrm{PR}=1.16)$ among the ones who had wage losses. Brazilian pediatric dentists have knowledge about COVID-19, and attitudes in their clinical routines changed due the pandemic. Financial life was harmed and a negative impact of the pandemic in psychosocial aspects of workers was found.

Keywords: Pediatric Dentistry; Prospective Studies; COVID-19.

\section{Introduction}

In March 2020, the World Health Organization declared a pandemic due to COVID-19. The Coronavirus Disease-2019, caused by the coronavirus (SARS-CoV-2), has been spreading exponentially, causing thousands of deaths worldwide. ${ }^{1}$ SARS-CoV-2 can be transmitted directly and indirectly. Aerosols and droplets are considered the main means of spreading and dissemination of the disease. ${ }^{2}$ These findings reinforce the need for effective preventive measures for biosafety in dental offices.

In addition to the constant vigilance needed in implementing COVID-19 control measures, the pandemic has had a series of psychosocial implications, affected individuals of different social classes. ${ }^{3}$ During a pandemic, fear increases anxiety and stress levels in healthy individuals and intensifies the symptoms of pre-existing psychiatric disorders. ${ }^{4}$ Mental health tends to 
be impacted in individuals affected by the infection. ${ }^{5}$ Uncertainties stemming from the pandemic have consequences in several sectors, with direct implications in everyday life and mental health.

Healthcare workers have been at the forefront of the COVID-19 response and are considered the most psychologically affected group; they face an increased workload, fear of contaminating themselves and family members, misinformation, and anger due to a lack of professional support. ${ }^{3}$ Dentists must adapt to this new situation. The use of personal protective equipment (PPE), while a part of standard practice, has increased fear and anxiety in dental offices. Pediatric dentists work with children, who are considered potential vectors of the disease, as they may be asymptomatic, present mild symptoms, carry the virus, and spreading the infection. ${ }^{6}$

Recently, a cross-sectional online survey assessed dentists from different specialties for their knowledge and perceptions of COVID-19, and among them, oral maxillofacial surgeons showed higher knowledge scores. ${ }^{7}$ In the state of São Paulo, Brazil, a cross-sectional study evaluated the impact of the pandemic among dentists, and $83 \%$ reported not having any specific training to control the transmission of coronavirus. ${ }^{8}$ This research aimed to understand the attitudes adopted by pediatric dentists, and to identify psychosocial aspects related to the COVID-19 pandemic.

\section{Methodology}

\section{Ethical considerations}

This project was approved by the Research Ethics Committee of the Ribeirão Preto School of Dentistry / University of São Paulo (CAAE 33334620.2.0000.5419).

\section{Study design}

A cross-sectional study with primary data collection through a structured questionnaire.

\section{Formulation of questionnaires}

A Google Forms (Google Inc., Mountain View, USA) questionnaire was developed and sent by e-mail and WhatsApp (WhatsAPP Inc., Mountain View, USA) to Brazilian pediatric dentists weekly, from July 3 to
August 4, 2020, consolidating convenience sampling. The survey was divided into Section A (demographic information and professional characteristics); Section B (symptoms, mode of transmission, control measures, and patients with COVID-19 treating attitude), and Section C (psychosocial aspects).

\section{Statistical analysis}

The information collected was pre-processed to validate the responses and eliminate errors and duplications in electronic spreadsheets. We performed a descriptive analysis using absolute (n) and relative (percentage) frequencies. A chi-square association test and log-linear regression models were used to estimate the prevalence ratio to verify the association of income loss with psychosocial aspects. ${ }^{7}$ In all analyses, we used a significance level of $5 \%$.

\section{Results}

Of the 508 Brazilian pediatric dentists surveyed, 58 were duplicated, so the sample comprised 450 questionnaires. Most were female (95.5\%) aged between 31 and 50 years (56\%). The number of professionals who graduated from public and private schools did not vary, and the highest average time since graduation ranged from 21 to 25 years (18.2\%), with a specialist's degree (62.4\%), master's degree (18.89\%), and doctorate degree $(18.67 \%)$ in pediatric dentistry. Most professionals worked in private practice, with a workload between 31 and 40 hours per week (37.6\%) (Table 1).

Most pediatric dentists were aware of the disease incubation period: from 1 to 14 days $(62.44 \%)$, ways of transmission: coughing/sneezing (99.11\%); handshake (82.44\%); touching contaminated surface $(91.33 \%)$, the symptoms: fever (99.78\%); cough (96.44\%); difficulty in breathing (99.33\%); myalgia and fatigue $(78.22 \%)$; sore throat (67.56\%); red eyes (82.22\%); vomiting (56\%); and rashes $(29.56 \%)$, and $69.33 \%$ understand that patients with COVID-19 may be asymptomatic. The majority performed handwashing before and after patient care (99.56\%) and utilized alcohol-based hand sanitizer for disinfection (98.89\%). The N95 mask was used by $78.67 \%$ of the professionals, while $54.22 \%$ merely used the surgical mask, and $43.33 \%$ adhered to the overlay 
Table 1. General characterization of the 450 Brazilian pediatric dentists evaluated.

\begin{tabular}{|c|c|c|}
\hline Variable & $\begin{array}{c}\text { Absolute } \\
\text { frequency } \\
\text { (n) }\end{array}$ & $\begin{array}{c}\text { Relative } \\
\text { frequency } \\
(\%)\end{array}$ \\
\hline \multicolumn{3}{|l|}{ Sex } \\
\hline Female & 430 & 95.56 \\
\hline Male & 20 & 4.44 \\
\hline \multicolumn{3}{|l|}{ Age group (years) } \\
\hline $20-30$ & 87 & 19.33 \\
\hline $31-40$ & 109 & 24.22 \\
\hline $41-50$ & 143 & 31.78 \\
\hline $51-60$ & 93 & 20.67 \\
\hline Over 60 & 18 & 4.00 \\
\hline \multicolumn{3}{|c|}{ Institution you graduated from } \\
\hline Private & 228 & 50.67 \\
\hline Public & 222 & 49.33 \\
\hline \multicolumn{3}{|l|}{ Education } \\
\hline Specialist's degree & 281 & 62.44 \\
\hline Master's degree & 85 & 18.89 \\
\hline Doctor's degree & 84 & 18.67 \\
\hline \multicolumn{3}{|c|}{ Years after completing graduate studies } \\
\hline $0-5$ & 166 & 36.89 \\
\hline $6-10$ & 64 & 14.22 \\
\hline $11-15$ & 58 & 12.89 \\
\hline $16-20$ & 61 & 13.56 \\
\hline $21-25$ & 56 & 12.44 \\
\hline $26-30$ & 31 & 6.89 \\
\hline Over 30 & 14 & 3.11 \\
\hline \multicolumn{3}{|l|}{ Weekly workload (hours) } \\
\hline $11-20$ & 87 & 19.33 \\
\hline $21-30$ & 86 & 19.11 \\
\hline $31-40$ & 169 & 37.56 \\
\hline $41-50$ & 62 & 13.78 \\
\hline $51-60$ & 14 & 3.11 \\
\hline Over 60 & 12 & 2.67 \\
\hline Not currently working & 20 & 4.44 \\
\hline
\end{tabular}

of the two masks. The faceshield was used by $83.11 \%$ of pediatric dentists, and $64.22 \%$ reported difficulties in working with children due to the implementation of these extra PPE.

Pediatric dentists reported cases involving only urgencies and emergencies (38\%), and 59.78\% performed invasive procedures. Concerning the use of handpieces, $59.56 \%$ used high-speed and $71.33 \%$ used low-speed handpieces. Regarding cariostatics, $33.56 \%$ stated that they used the product before, $8.44 \%$ started using it during the pandemic, while $46 \%$ did not use it. With respect to chemomechanical caries removal, $35.56 \%$ integrated this procedure into clinical practice, $6.22 \%$ introduced the treatment during the pandemic period, and $44 \%$ did not use it.

A high percentage $(74.22 \%)$ of respondents stated that they had postponed all patients' treatments during this period. Most dentists (92.22\%) reported that they did not take care or did not know if any patient who was undergoing dental treatment tested positive for COVID-19 and 7.78\% treated a patient with COVID-19.

Among the respondents, 59.11\% felt unsafe about performing dental care during the pandemic period, $50.67 \%$ reported fear, $83.78 \%$ felt more stress during this period, $49.56 \%$ experienced insomnia, and $17.5 \%$ sought help to overcome emotional symptoms. Regarding medication use, $15.67 \%$ used herbal medicines, $7.11 \%$ used homeopathic medicines, and $17.78 \%$ used anxiolytics or antidepressants. Regarding finances, $34.44 \%$ reported over a 50\% reduction in earnings, $33.78 \%$ reported losses between 20 and 50\%, 16\% had less than a $20 \%$ loss, and $15.11 \%$ had no lost wages. Most felt distraught by the government and representative councils and $61.68 \%$ feared the future of the field (Table 2).

Table 3 shows the association between the psychosocial aspects of professionals who had lost wages (between $20-50 \%$ and higher than $50 \%$ ), compared to those who had no financial loss or losses less than $20 \%$. The fear of the future $(P R=1.21)$ and the use of medication (anxiolytics, antidepressants, herbal remedies, homeopathic medicines for anxiety, depression, and insomnia) increased $(P R=1.16)$ among individuals who had lost wages.

\section{Discussion}

This study provides a panoramic view of the COVID-19 pandemic among Brazilian pediatric dentists. A survey utilizing the Google Forms questionnaire was sent by the Internet, which allowed 
Knowledge, attitudes, and psychosocial impacts among Brazilian Pediatric Dentists during COVID-19 pandemic

Table 2. Characterization of the psychosocial aspects of the Brazilian pediatric dentists evaluated.

\begin{tabular}{|c|c|c|}
\hline Psychosocial aspect & Absolute frequency (n) & Relative frequency (\%) \\
\hline \multicolumn{3}{|c|}{ Do you feel UNSAFE + B3:B37+B3:B35to attend pediatric patients? } \\
\hline No & 184 & 40.89 \\
\hline Yes & 266 & 59.11 \\
\hline \multicolumn{3}{|c|}{ Are you afraid to attend pediatric patients? } \\
\hline No & 222 & 49.33 \\
\hline Yes & 228 & 50.67 \\
\hline \multicolumn{3}{|c|}{ Did you feel more STRESSED after the pandemic started? } \\
\hline No & 73 & 16.22 \\
\hline Yes & 377 & 83.78 \\
\hline \multicolumn{3}{|c|}{ Have you experienced insomnia after the pandemic started? } \\
\hline No & 227 & 50.44 \\
\hline Yes & 223 & 49.56 \\
\hline
\end{tabular}

Did you seek professional help to overcome emotional symptoms associated with this pandemic situation that we are facing?

$\begin{array}{rrr}\text { No } & 368 & 81.78 \\ \text { Yes } & 82 & 18.22\end{array}$

Did you need to utilize any of these MEDICATIONS during this pandemic period?

Anxiolytic

No $\quad 398$

88.44

Yes

52

11.56

Antidepressants

No

Yes

Herbal remedies

$\mathrm{No}$

Yes

Homeopathic medicines

No

Yes

Others

$\begin{array}{lcr}\text { No } & 412 & 91.56 \\ \text { Yes } & 38 & 8.44\end{array}$

I did not have to use any

No

Yes

Do you feel distraught by the government and representative councils in this pandemic?

No

Yes

Have you had your "FINANCIAL LIFE" affected by the pandemic?

Between 20-50\%

More than $50 \%$

Less than $20 \%$

There was no decline in my financial life

Do you FEAR for the future of your practice as a post-pandemic pediatric dentist?

$\begin{array}{llr}\text { No } & 172 & 38.22 \\ \text { Yes } & 278 & 61.78\end{array}$


Table 3. Associations of income loss during the pandemic and psychosocial aspects.

\begin{tabular}{|c|c|c|c|c|c|}
\hline \multirow{3}{*}{ Psychosocial aspects } & \multicolumn{2}{|c|}{ Loss of income } & \multirow{3}{*}{ Prevalence ratio } & \multirow{3}{*}{ IC $95 \%$} & \multirow{3}{*}{$\mathrm{p}$-value } \\
\hline & Yes & No & & & \\
\hline & $\mathrm{n}(\%)$ & n (\%) & & & \\
\hline \multicolumn{6}{|l|}{ Unsafe } \\
\hline Yes & $187(0.61)$ & $79(0.55)$ & 1.08 & (0.95 1.23$)$ & 0.3 \\
\hline No & $120(0.39)$ & $64(0.45)$ & Ref. & Ref. & \\
\hline \multicolumn{6}{|l|}{ Fear } \\
\hline Yes & $156(0.51)$ & $72(0.5)$ & 1.01 & (0.89 1.14$)$ & \\
\hline No & $151(0.49)$ & $71(0.5)$ & Ref. & Ref. & 0.99 \\
\hline \multicolumn{6}{|l|}{ Stress } \\
\hline Yes & $260(0.85)$ & $117(0.82)$ & 1.07 & (0.89 1.29) & 0.52 \\
\hline No & $47(0.15)$ & $26(0.18)$ & Ref. & Ref. & \\
\hline \multicolumn{6}{|l|}{ Insomnia } \\
\hline Yes & $159(0.52)$ & $64(0.45)$ & 1.09 & (0.96 1.24$)$ & 0.19 \\
\hline No & $148(0.48)$ & $79(0.55)$ & Ref. & Ref. & \\
\hline \multicolumn{6}{|l|}{ Professional help } \\
\hline Yes & $54(0.18)$ & $28(0.20)$ & 0.96 & $(0.811 .14)$ & 0.7 \\
\hline No & $253(0.82)$ & $115(0.80)$ & Ref. & Ref. & \\
\hline \multicolumn{6}{|l|}{ Use of medication } \\
\hline Yes & $204(0.66)$ & $80(0.56)$ & 1.16 & (1.01 1.33$)$ & 0.04 \\
\hline No & $103(0.34)$ & $63(0.44)$ & Ref. & Ref. & \\
\hline \multicolumn{6}{|l|}{ Fear for the future } \\
\hline Yes & $203(0.66)$ & $75(0.52)$ & 1.21 & (1.05 1.39) & 0.007 \\
\hline No & $104(0.34)$ & $68(0.48)$ & Ref. & Ref. & \\
\hline
\end{tabular}

Ref.: denominator of the prevalence ratio.

for a wide coverage. This survey was consistent with that of previous studies, and it allowed a wide coverage, due to the ease of access. ${ }^{9-11}$ Most respondents (95.56\%) were women, which reflects the predominance of female pediatric dentists in Brazil. In 2020, a study showed that among pediatric dentists in England, the proportion of women was almost three times that of men.12 In the United States of America, research showed that between 2010 and 2016, the largest growth among female dentists was in pediatric dentistry $(44.3 \%){ }^{13}$ Most pediatric dentists are in the age range of 31 to 50 years, have held their degree for more than 20 years, and possess a Specialist's degree (62.4\%) in pediatric dentistry.

The surveyed professionals were aware of the disease incubation period, transmission methods, and symptoms of COVID-19. Nonetheless, the clinical manifestations of COVID-19 in children are not as clear as in adults. Bi et al. (2020) ${ }^{14}$ conducted an assessment in China with over 2000 children with suspected or diagnosed COVID-19, and found that over $90 \%$ were asymptomatic or had only moderate symptoms. Another study, which analyzed 2,143 infected Chinese children, indicated that $4 \%$ were asymptomatic, $51 \%$ had mild symptoms, $39 \%$ were moderate, and $6 \%$ were in a critical state. The proportion of severe cases varied according to the age group, with $11 \%$ in children under 1 year old, 7\% between 1 and 5 years, $4 \%$ from 6 to 10 years, $4 \%$ in children aged 11 to 15 years, and $3 \%$ in children aged 16 to 19 years old. ${ }^{15}$ Other researchers have inferred that infected children may be asymptomatic or have abdominal discomfort, nausea, vomiting, abdominal pain, and diarrhea. Nevertheless, they reinforce that these 
children have mild clinical manifestations, usually have a good prognosis, and recover within 1 and 2 weeks. ${ }^{16,17}$ Recently, a systematic review of COVID-19 in pediatric patients concluded that this virus also affects children and causes systemic disease involving several internal organs; in addition, the prevalence, severity, and diversity of the symptoms are lower than in adults. The most common symptoms are cough and fever, followed by gastrointestinal manifestations, and the risk of severe COVID-19 is greater in children with comorbidities. In addition, this research highlighted increased rates of anxiety and depression due to the isolated situation. ${ }^{18}$ Therefore, this disease profile in children puts them at higher risk of potential COVID-19 transmission. Pediatric dentists must be aware of all possible manifestations of the disease to take stringent transmission control measures in the clinical environment.

Biosafety in dental offices has always been a concern among dentists. The physical proximity between patients and professionals, the aerosol generated instruments, such as high-speed handpieces and Cavitron cleaners, and contact with saliva and blood, expose dental professionals to potential contamination. In this study, we found that infection control measures such as handwashing and disinfecting with alcoholbased sanitizer were common among pediatric dentists (99.6\% and $98.89 \%$, respectively). Almost $80 \%$ wore N95 masks and $83.11 \%$ wore faceshields, and many even reported difficulty in practicing on children due to the extra PPE. These findings are supported by Consolo et al., ${ }^{19}$ who reported that $77 \%$ of dentists increased the PPE use due to the COVID-19 pandemic. The increasing demand for PPE inflated the price of these products, contributing to the financial crisis; $34.44 \%$ of respondents stated that there was over a $50 \%$ reduction in earnings and $33.78 \%$ reported losses between 20 to $50 \%$. Moreover, over $70 \%$ reported postponing dental treatment. These data agree with a recent Brazilian National online survey led by Morais et al. (2020), ${ }^{20}$ which showed that the number of patients receiving dental treatment significantly decreased, with most receiving urgent and emergency care.

Since March 20, 2020, the National Health Surveillance Agency (ANVISA) in Brazil has recommended that only emergency and dental care be performed, and the Federal Council of Dentistry advised the use of non-invasive procedures. ${ }^{21}$ Therefore, procedures that do not generate aerosols, such as atraumatic restorations, cariostatic restorations, and chemomechanical caries removal, have been recommended..$^{22-24}$ In the present study, Brazilian pediatric dentists used more low-speed handpieces (71.33\%) than high-speed (59.56\%). A small number of dentists adhered to the guideline of cariostatic $(8.44 \%)$ and chemomechanical agent use (6.22\%).

Regarding the psychological implications, uncertainty in dental practice, fear, and stress were evident, along with insomnia, which appeared in almost $50 \%$ of professionals. Many reported taking some medication to control such symptoms, such as herbal medicine, homeopathic and anxiolytics, or antidepressants. Our data support other studies that found high anxiety levels, stress symptoms, and other emotional disorders among distinct healthcare workers. In China, the originating location of the outbreak, anxiety, depression, and stress have been identified among healthcare workers. ${ }^{25}$ Lai et al. ${ }^{26}$ found a higher occurrence of both insomnia and distress.

In an online cross-sectional survey on the impact of COVID-19 pandemic among physicians, nurses, and dentists in Brazil, aside from experiencing the most job loss, dentists presented more anxiety and stress symptoms and difficulty sleeping. ${ }^{27}$ Petzold et al. (2020) ${ }^{3}$ inferred that social support, communication, distribution of tasks, flexible working hours, and psychological aid must be implemented to decrease emotional stress. Our data reveal that a large percentage of pediatric dentists feel distraught by the government and representative councils and fear the future, and it is up to the representative councils to develop and provide care and support strategies. Our results corroborate with the literature, when assessing the association between psychosocial aspects related to lost wages (between $20-50 \%$ and higher than $50 \%$ ) among pediatric dentists. We found that fear of the future and the use of medication for anxiety, depression, and insomnia was higher among those who suffered wage losses.

It is evident that the COVID-19 pandemic has influenced Brazilian pediatric dentists. It should 
also be stressed that pediatric dentistry has some peculiarities, including close professional contact with children, behavioral management techniques such as protective stabilization, the use of cheek retractors, and the use of playful objects, such as dolls and toys, all of which facilitate care for noncooperative children. The impracticality of performing behavior management techniques with extra PPE, such as the faceshield or N95 mask, presents an additional challenge to the practice of pediatric dentistry. Another anomaly in pediatric dentistry is the need for an adult present, who is responsible for the child during the appointments. However, this increases the number of people involved in clinical care, further exposing them to possible SARS-CoV-2 contamination. Currently, people are better adapted to the conditions and regulations imposed by the pandemic. Elective care in private dental offices and public clinics is gradually being reinstated, and it is likely that professionals and patients have adapted to all the new measures. Thus, questionnaires, as in the present study, should be applied to monitor the ongoing status of pediatric dentistry in Brazil.

Despite the limitations in data collection, due to conflicting schedules or difficulty with electronic forms, we identifed an urgent need to improve the pediatric clinic routine. Dental care cannot be neglected, even during a pandemic. Children's dental care is fundamental, as orofacial pain has a negative impact on children's quality of life. ${ }^{27}$ Chisini et al. ${ }^{28}$ conducted a study in the public national systems in Brazil, and showed a $89 \%$ decrease in children's dental practice in April 2020, a peak of the pandemic. Witton et al. ${ }^{29}$ conducted a qualitative research study in England to identify dental reforms post-pandemic, and reported that children's oral health was harmed due to the suspension of elective treatments. Therefore, the researchers recommended the creation of child oral health programs post-pandemic. Kochhar et al. ${ }^{30}$ stressed that children should feel comfortable with the extra PPE in order to reduce fear and increase cooperation. Pediatric dentists must stay up to date on COVID-19 prevention measures, conduct training, and follow biosafety protocols to minimize the negative effect that the pandemic may have on children's dental health.

\section{Conclusion}

This study showed that Brazilian pediatric dentists are knowledge about COVID-19 symptoms, and the attitudes in their clinical routines have changed due to the pandemic. There was a decrease in the number of patients, and the changes in PPE made the practice of pediatric dentistry more difficult. Regarding psychosocial aspects, lack of safety, fear, stress, and insomnia were reported by most pediatric dentists, and medications such as herbal medicines, homeopathic and anxiolytics, or antidepressants, have been used to overcome emotional distress. The financial lives of these professionals were harmed, and fear of the future and the use of medication for anxiety, depression, and insomnia were more common among those who had wage losses between $20-50 \%$ and higher than $50 \%$. More support strategies must be provided by the government and representative councils to minimize the economic and emotional impacts of the COVID-19 pandemic on Brazilian pediatric dentists.

\section{Acknowledgements}

We thank all Brazilian pediatric dentists who voluntarily answered the online questionnaire, which supported this research.

\section{References}

1. World Health Organization. Novel Coronavirus (2019-nCoV): situation report Geneva: World Health Organization; 2020.

2. Centers for Disease Control and Prevention. Transmission of coronavirus disease 2019 COVID-19. Washington, DC: Centers for Disease Control and Prevention; 2020 [cited 2020 Mar 18]. Available from: https://www.cdc.gov/coronavirus/2019ncov/about/transmission.html

3. Petzold MB, Plag J, Ströhle A. [Dealing with psychological distress by healthcare professionals during the COVID-19 pandemia]. Nervenarzt. 2020 May;91(5):417-21. German. https://doi.org/10.1007/s00115-020-00905-0 
Knowledge, attitudes, and psychosocial impacts among Brazilian Pediatric Dentists during COVID-19 pandemic

4. Shigemura J, Ursano RJ, Morganstein JC, Kurosawa M, Benedek DM. Public responses to the novel 2019 coronavirus (2019-nCoV) in Japan: mental health consequences and target populations. Psychiatry Clin Neurosci. 2020 Apr;74(4):281-2. https://doi.org/10.1111/pcn.12988

5. Reardon S. Ebola's mental-health wounds linger in Africa. Nature. 2015 Mar;519(7541):13-4. https://doi.org/10.1038/519013a

6. Kelvin AA, Halperin S. COVID-19 in children: the link in the transmission chain. Lancet Infect Dis. 2020 Jun;S1473-3099(20)30236-X. https://doi.org/10.1016/S1473-3099(20)30236-X

7. Aldhuwayhi S, Mallineni SK, Sakhamuri S, Thakare AA, Mallineni S, Sajia R, et al. Covid-19 Knowledge and perceptions among dental specialists: a cross-sectional online questionnaire survey. Risk Manag Healthc Policy. 2021 Jul 7;14:2851-2861. https://doi.org/10.2147/RMHP.S306880

8. Novaes TF, Jordão MC, Bonacina CF, Veronezi AO, Araujo CA, Olegário IC, et al. COVID-19 pandemic impact on dentists in Latin America's epicenter: São-Paulo, Brazil. PLoS One. 2021 Aug;16(8):e0256092. https://doi.org/10.1371/journal.pone.0256092

9. Iqbal MR, Chaudhuri A. COVID-19: results of a national survey of United Kingdom healthcare professionals' perceptions of current management strategy: a cross-sectional questionnaire study. Int J Surg. 2020 Jul;79:156-61. https://doi.org/10.1016/j.ijsu.2020.05.042

10. Cotrin P, Moura W, Gambardela-Tkacz CM, Pelloso FC, Santos LD, Carvalho MD, et al. Healthcare workers in Brazil during the COVID-19 pandemic: a cross-sectional online survey. Inquiry. 2020 Jan-Dec;57:46958020963711. https://doi.org/10.1177/0046958020963711

11. Moraes RR, Correa MB, Daneris Â, Queiroz AB, Lopes JP, Lima GS, et al. E-mail vs. Instagram recruitment strategies for online survey research. Braz Dent J. 2021 Jan-Feb;32(1):67-77. https://doi.org/10.1590/0103-6440202104291

12. Newton JT, Thorogood N, Gibbons DE. The work patterns of male and female dental practitioners in the United Kingdom. Int Dent J. 2000 Apr;50(2):61-8. https://doi.org/10.1002/j.1875-595X.2000.tb00800.x

13. Surdu S, Mertz E, Langelier M, Moore J. Dental Workforce Trends: A National Study of Gender Diversity and Practice Patterns. Med Care Res Rev. 2020 Feb;28:1077558720952667. https://doi.org/10.1177/1077558720952667

14. Bi Q, Wu Y, Mei S, Ye C, Zou X, Zhang Z et al. Epidemiology and Transmission of COVID-19 in Shenzhen China: analysis of 391 cases and 1,286 of their close contacts. Med Rxiv Aug;20(8):911-9. https://doi.org/10.1016/S1473-3099(20)30287-5

15. Dong L, Tian J, He S, Zhu C, Wang J, Liu C, et al. Possible vertical transmission of SARS-CoV-2 from an infected mother to her newborn. JAMA. 2020 May;323(18):1846-8. https://doi.org/10.1001/jama.2020.4621

16. Chen H, Guo J, Wang C, Luo F, Yu X, Zhang W, et al. Clinical characteristics and intrauterine vertical transmission potential of COVID-19 infection in nine pregnant women: a retrospective review of medical records. Lancet. 2020 Mar;395(10226):809-15. https://doi.org/10.1016/S0140-6736(20)30360-3

17. Zhang YH, Lin DJ, Xiao MF, Wang JC, Wei Y, Lei ZX, et al. [2019-novel coronavirus infection in a three-month-old baby]. Zhonghua Er Ke Za Zhi. 2020 Feb;58(0):E006. https://doi.org/10.3760/cma.j.issn.0578-1310.2020.0006

18. Mehraeen E, Oliaei S, SeyedAlinaghi S, Karimi A, Mirzapour P, Afsahi AM, et al. COVID-19 in pediatrics: the current knowledge and practice. Infect Disord Drug Targets. 2021 Sep;21: https://doi.org/10.2174/1871526521666210929121705

19. Consolo U, Bellini P, Bencivenni D, lani C, Checchi V. Epidemiological aspects and psychological reactions to COVID-19 of dental practitioners in the Northern Italy Districts of Modena and Reggio Emilia. Int J Environ Res Public Health. 2020 May;17(10):3459. https://doi.org/10.3390/ijerph17103459

20. Moraes RR, Correa MB, Queiroz AB, Daneris Â, Lopes JP, Pereira-Cenci T, et al. COVID-19 challenges to dentistry in the new pandemic epicenter: brazil. PLoS One. 2020 Nov;15(11):e0242251. https://doi.org/10.1371/journal.pone.0242251

21. Mallineni SK, Innes NP, Raggio DP, Araujo MP, Robertson MD, Jayaraman J. Coronavirus disease (COVID-19): characteristics in children and considerations for dentists providing their care. Int J Paediatr Dent. 2020 May;30(3):245-50. https://doi.org/10.1111/ipd.12653

22. Asociación Latinoamericana de Odontopediatría. Tratamiento de la enfermedad de caries en época de COVID-19: protocolos clínicos para el control de aerosoles. Rev Odontopediatr Latinoam Odontop. 2020;10(2):1-28.

23. Li T, Zhai X, Song F, Zhu H. Selective versus non-selective removal for dental caries: a systematic review and meta-analysis. Acta Odontol Scand. 2018 Mar;76(2):135-40. https://doi.org/10.1080/00016357.2017.1392602

24. Seifo N, Cassie H, Radford JR, Innes NP. Silver diamine fluoride for managing carious lesions: an umbrella review. BMC Oral Health. 2019 Jul;19(1):145. https://doi.org/10.1186/s12903-019-0830-5

25. Yang Y, Li W, Zhang Q, Zhang L, Cheung T, Xiang YT. Mental health services for older adults in China during the COVID-19 outbreak. Lancet Psychiatry. 2020 Apr;7(4):e19. https://doi.org/10.1016/S2215-0366(20)30079-1

26. Lai J, Ma S, Wang Y, Cai Z, Hu J, Wei N, et al. Factors associated with mental health outcomes among health care workers exposed to Coronavirus disease 2019. JAMA Netw Open. 2020 Mar;3(3):e203976. https://doi.org/10.1001/jamanetworkopen.2020.3976

27. Barasuol JC, Garcia LP, Freitas RC, Dalpian DM, Menezes JV, Santos BZ. Dental care utilization among children in Brazil: an exploratory study based on data from national household surveys. Cien Saude Colet. 2019 Feb;24(2):649-57. https://doi.org/10.1590/1413-81232018242.03232017 
28. Chisini LA, Costa FD, Demarco GT, Silveira ER, Demarco FF. COVID-19 pandemic impact on paediatric dentistry treatments in the Brazilian Public Health System. Int J Paediatr Dent. 2021 Jan;31(1):31-4. https://doi.org/10.1111/ipd.12741

29. Witton R, Plessas A, Wheat H, Baines R, Delgado MB, Mills I, et al. The future of dentistry post-COVID-19: perspectives from Urgent Dental Care centre staff in England. Br Dent J. 2021 Sep;1-5: https://doi.org/10.1038/s41415-021-3405-1

30. Kochhar AS, Bhasin R, Kochhar GK, Dadlani H, Thakkar B, Singh G. Dentistry during and after COVID-19 Pandemic: pediatric Considerations. Int J Clin Pediatr Dent. 2020 Jul-Aug;13(4):399-406. https://doi.org/10.5005/ip-journals-10005-1782 